\title{
LA SIGNIFICACIÓN DEL CONCEPTO DE SENTIDO EN LA DOCTRINA PRÁCTICA DE LOS POSTULADOS DE KANT
}

Kant distingue en sus Criticas cuatro clases de postulados:

a) Afirmaciones dogmáticas, que consisten en "hacer pasar una proposición como inmediatamente cierta sin justificación o prueba" (R. p. $A$, 233).* Estas no son permitidas científicamente. Pues "si [...] al concepto de una cosa le sobreviene una determinación de modo sintético a priori, tiene que añadirse indefectiblemente respecto de tal proposición, cuando no una prueba, sí por lo menos una deducción de la legitimidad de su afirmación" (R. p. A, 233). Afirmaciones dogmáticas contradicen, por tanto, la exigencia básica de la filosofía trascendental, de demostrar la posibilidad del saber conocitivo.

b) Postulados matemáticos. Son "proposiciones prácticas, [que] no contienen otra cosa sino la síntesis mediante la cual nos damos primeramente un objeto y producimos su concepto" (R. p. A, 234). Ast, por ejemplo, cuando se pide "trazar un círculo con una línea dada sobre una superficie desde un punto dado". "Una proposición semejante no puede ser demostrada, porque el procedimiento que requiere es justamente aquello mediante lo cual producimos en primer lugar el concepto de tal figura" (R. p. $A$, 234).

c) En la Critica de la Razón Pura Kant entiende especialmente bajo postulados las "reglas del empleo objetivo" de las categorías de la modalidad (R. p. $A, 161)$. Éstas son "aclaraciones de los conceptos de posibilidad, realidad y necesidad en su empleo empírico, y con esto al mismo tiempo restricciones de todas las categorías al empleo meramente empírico" $(R$. p. $A, 219$ ). "Concierne a la síntesis de la mera intuición (de la forma del fenómeno), de la percepción (de la materia del mismo) y de la experiencia (de la relación de estas percepciones) en conjunto."

d) Postulados prácticos, es decir, "proposiciones teoréticas, pero no demostrables como tales, en cuanto que dependen inseparablemente de una ley práctica válida a priori en forma incondicionada" ( $R$. pr., 220).

- Abreviaturas. R. p.: Razón pura (Critica de la), A: primera edición; B: segunda edición. Los números remiten, como es usual, a las páginas de las ediciones alemanas originales. R. pr.: Razón práctica (Critica de la). Cr. J.: Critica del Juicio. Re.l.p. r.: La Religión en los limites de la pura razón. F. m. c.: Fundamentación de la Metafisica de las costumbres. Las traducciones de las citas son personales del traductor de este articulo. 
Las exposiciones siguientes se ocupan sólo de los postulados prácticos nombrados en último término. Yo planteo la cuestión: "iSostiene Kant tales postulados prácticos legitimamente $\rightarrow$ en caso de que si, con qué derecho?" La cuestión implica que Kant afirma postulados prácticos (I).

Kant los sostiene como:

a) exigencias práctico-necesarias para un ser racional finito, derivadas de la ley moral, que se refiere a la voluntad.

A la objeción de Wizenmann, quien opinaba que la introducción de los postulados tenía como fin permitir que se tuviera por existente todo lo que deseara la calenturienta fantasía, contesta Kant: "Aquí es [...] una necesidad de la razón derivada de un fundamento objetivo de determinación de la voluntad, es decir, procedente de la ley moral, que ata necesariamente a todo ser racional, que legitima a priori, por tanto, para presuponer en la naturaleza las condiciones correspondientes a la voluntad y que hace a tales condiciones inseparables del empleo práctico total de la razón. Es un deber hacer real el bien supremo según nuestra máxima capacidad; de ahí que, sin duda, debe ser también posible: por ende, es también inevitable para todo ser racional [...], presuponer aquello que es necesario para su posibilidad objetiva. La presuposición es tan necesaria como la ley moral y únicamente en relación con ella es válida" (R. pr., 259, Nota).

Postulados prácticos son: $b$ ) exigencias de determinadas presuposiciones teoréticas. Se trata, como dice Kant expresamente muchas veces, de "proposiciones teoréticas" (R. pr., 220), o bien, "conceptos", "ciertas posiciones teoréticas" (R. pr., 216), "presuposiciones [...] teoréticas", "no [...] dogmas" (R. pr., 238).

Postulados prácticos son: c) presuposiciones de una determinada exist tencia. La ley práctica postula la "realidad objetiva" de tres "conceptos teoréticos" (R. pr., 241), "con lo cual [...] el conocimiento teorético de la razón pura [...] recibe un aumento, que sin embargo sólo consiste en que aquellos conceptos, de otro modo problemáticos (meramente pensables) para ella, son aclarados ahora asertóricamente como tales y corresponden a ellos objetos reales" (R. pr., 242).

d) Estos objetos son condiciones de posibilidad de la realización del objeto práctico (del bien supremo), pero con ello a la vez también condiciones de posibilidad de la observancia de la ley moral; y con ello finalmente condiciones de posibilidad de la ley moral, para enlazarla con la realización del bien supremo.

Kant llama a los objetos postulados, "existentes en la naturaleza de las 
cosas" (R. pr., 258), "condicion[es] de posibilidad del objeto de una voluntad determinada por aquella ley" (R. pr., 240); condiciones de la posibilidad "de hacer real el objeto necesario de la razón pura práctica (el bien supremo)" (R. pr., 244). Kant los designa, por sobre esto, como condiciones "en atención al sujeto para la observancia [de la ley moral]" (R. pr., 23. Nota) y finalmente, como "condicion[es] de posibilidad de la fuerza obligatoria" de una ley práctica absolutamente necesaria (R. p. $A, 634)$.

Con referencia a a):

Los postulados provienen inmediatamente de la voluntad moral, mediatamente de la ley moral: "los [postulados] emanan todos del principio de la moralidad, que no es un postulado, sino una ley, con la cual la razón determina mediatamente a la voluntad, voluntad que, precisamente por estar determinada así, como voluntad pura, exige esta condición necesaria de la observancia de su precepto" ( $R$. pr., 268).

Sin embargo, según las presuposiciones kantianas la voluntad por sí sola no puede contener el fundamento legitimo de esas exigencias. Que "la razón práctica se extienda más allá [de la ley moral, es] posible en virtud de que ésta es relacionada con la propiedad natural del hombre de tener que proponerse para todas las operaciones, además de la ley, aún un fin" (Re. r. p. r., XII, Nota). En esto se funda su relativa subjetividad, que los pone en la cercanía de ficciones ("enajenamientos", "presuposiciones"). Los postulados son algo, "cuyo concepto no puede ser demostrado en ninguna experiencia posible para nosotros, y por ende suficiente para el empleo teorético de la razón según su realidad objetiva, cuyo empleo, sin embargo, es mandado por la razón pura práctica para la mejor realización posible de aquel fin, y por lo mismo tiene que ser admitido como posible" (Cr. $J$, 457 y s.).

Con referencia a $b$ ):

Los postulados resultan, según esto, de la aplicación de la ley moral a la realidad empirica.

-a la voluntad (R. pr., 268);

- a "las condiciones de posibilidad del bien supremo existentes en la naturaleza de las cosas" ( $R$. pr., 258);

-a "la propiedad natural del hombre de tener que proponerse para todas las operaciones -[...] un fin" (Re. I. p. r., XII, Nota);

-a la necesidad de lograr causalidad en el mundo de la sensibilidad.

Postulados son, por tanto, exigencias de una relación enteramente determinada por la ley práctica y la realidad.

¿Cuál es esta realidad? Es: 1. la voluntad misma, y en ésta y por ésta también el apetito. 2. La realidad objetiva y su experiencia subjetiva (sentimiento de felicidad $\mathrm{e}$ infelicidad). 3. La relación recíproca entre voluntad y realidad objetiva. 
La exigencia de realidad de la ley moral en la voluntad conduce al postulado de la libertad; la exigencia de realidad de la ley moral en el mundo conduce al postulado de Dios.

Por tanto, como se muestra ya aquí, es puesta (postulada) por la razón una relación de la exigencia hacia la facticidad, y sólo con fundamento en la posición de esta relación se sostiene teoréticamente la existencia de ciertos objetos (a saber, de los que se postulan). La primera de estas dos posiciones, según Kant, jes práctical Los objetos de'la últimà, según Kant, permanecen "inintuibles". "Mas ahí no nos [es] dado nada de intuiciones [de estos objetos]" (R. pr., 242). Éstos, como todos los objetos, tienen que ser. pensados mediante categorías, aquí, por cierto, simplemente ser pensados. Kant los determina mảs de cerca como "ideas", que se vuelven "asertóricas" mediante la razón práctica, es decir, a las cuales tienen que corresponder objetos reales ( $R$. pr., $242-246$ ).

Pero Kant, de manera característica, ve una diferencia en el modus en que estas ideas son representadas, conforme a la realidad con que la exigencia se enlaza cada vez. La libertad es para él un hecho (res facti); el bien supremo, por el contrario, y las condiciones de su posibilidad: inmortalidad y Dios, son cosas de fe (res fidei). "Pero, lo que es muy de notar, se encuentra incluso entre los hechos una idea de la razón (que en sí no es capaz de una representación en la intuición [...]), y es la idea de la libertad, cuya realidad, como una especie particular de causalidad [...], se puede demostrar [...] en las operaciones reales, y por ende en la experiencia. La única entre todas las ideas de la razón pura, cuyo objeto es un hecho y que ha de ser contada también entre los scibilia" ( $C r . d . J ., 457$ ).

Respecto a $c$ ):

De acuerdo con muchos giros de Kant debería admitirse que los objetos que entran en cuestión aquí son hechos puros. Pero en realidad esta apreciación, por lo menos en el concepto de la libertad, no se puede sostener. La ley moral, que es cierta a priori, implica necesariamente la libertad. "Libertad y ley práctica incondicionada $[. .$.$] se remiten recíprocamente$ una a la otra" ( $R$. pr., 52). El conocimiento práctico va de la ley moral a la libertad. La libertad entra en la conciencia mediante la ley moral. La libertad, empero, pasa como "una especie particular de causalidad" "a operaciones reales" (Cr. d. J., 457). Con ello la voluntad moral es la realidad de la ley moral y de la libertad. La voluntad moral, por consiguiente, no es un mero factum, sino - aquí falta un término en Kant, que yo voy a suplir-: efectividad.

Lo mismo tiene que ser dicho necesariamente de Dios, pues es el "bien supremo originario", es decir, en El existe sólo voluntad pura; la ley moral no es en Él imperativa, sino ley; Él es santisimo. Sin duda esta realidad es 
solamente creída, pero lo que ahí se cree, no es un mero objeto fáctico, sino una efectividad.

Respecto de la inmortalidad y del bien supremo (dèrivado) podría parecer como si se tratara sólo de hechos, que ciertamente corresponden o convienen a una exigencia o mandato práctico. Con todo, esta concepción requiere luego en otra parte una efectividad: -a saber, en el hombre (ser moral) y en Dios ("propiedades de consumar el bien supremo", entre ellas, junto a otras, también la buena voluntad - la omnibondad).

- Respecto a $d$ ):

Como los postulados son condicionados por el bien supremo, importa, en primer lugar, aclarar la naturaleza de éste. El bien supremo se hace objeto de la moralidad, si la ley moral se manifiesta en un ser racional finito. Secundariamente, como dicho ser tiene que dirigir su obrar siempre según fines, el bien supremo como meta final se convierte en el fundamento de determinación de la voluntad moral.

El bien supremo, según Kant, es lo mandado, cuando el a priori de la ley moral se aplica, en el ser racional finito, a la sensibilidad. Tomado estrictamente, sin embargo, esto no es correcto. Pues sólo es mandada la subordinación del apetito bajo la forma de la ley. Con todo, voy a volver sobre 'esto todavía más adelante.

Los postulados son:

- Condiciones de posibilidad del bien supremo como objeto; por tanto,

- condiciones de la observancia de la ley moral; por ende,

- condiciones de la obligatoriedad del mismo para la voluntad.

Kant juzga aquí de este modo: el hombre moral tiene que "querer que exista absolutamente un mundo, porque la ley moral requiere que el bien supremo, posible mediante. nosotros, sea realizado" (Re. I. p. r IX). Sería "prácticamente imposible [...] tender hacia el objeto de un concepto, que en el fondo fuera vacio y $\sin$ objeto" ( $R$. pr., 257). Nuestra voluntad, sin embargo, no tiene una causalidad de esta especie en el mundo sensible, luego tiene que existir Dios, tiene que haber inmortalidad. "Como [...] el fomento del bien supremo, que encierra en su concepto esta conexión [de la felicidad con la virtud en el mundo], es un objeto a priori necesario de nuestra voluntad y está inseparablemente unido a la ley moral, por ello la imposibilidad del primero tiene que probar también la falsedad del segundo [de la ley moral]. Luego, si el bien supremo es imposible según las reglas prácticas, también la ley moral, que lo manda fomentar, tiene que ser ilusoria y orientada hacia vacíos fines inventados, y por ende falsa en si"' (R. pr., 205).

Para llegar a un juicio sobre la teoría de los postulados kantianos, pregun- 
témonos en adelante acerca del fundamento de legitimidad de los mismos. Esta pregunta se subdivide, con respecto al hecho de que se trata de una afirmación trascendental-filosófica, en las dos siguientes: 1. ¿Cómo debe considerarse la doctrina de los postulados de Kant? 2. ¿Es efectivamente correcta?

La validez a priori de la ley moral constituye el punto de partida de la seguridad gnoseológica de los postulados. La ley moral, según Kant, es "por decirlo así [...] un factum de la razón pura, del que somos conscientes a priori y que es cierto apodícticamente". No puede "ser demostrado a posteriori y, sin embargo, consta por sí mismo" (R. pr., 81 y s.).

Ahora bien, este conocimiento es sólo el conocimiento de una ley práctica, no uno de hechos o leyes teoréticos. "Como el imperativo sólo contiene, además de la ley, la necesidad de la máxima de ser conforme con esta ley, y la ley en cambio no encierra ninguna condición a la que esté restringida, no resta absolutamente otra cosa que la universalidad de una ley [es decir, ¡como contenido de la ley morall]" (F. m. c., ed. de la Ac., 421). La ley moral exige en consecuencia universalidad, y por cierto universalidad de los principios de las operaciones. "Toda ley práctica [representa] una operación posible [...] para un sujeto determinable prácticamente por la razón como algo necesario" (F. m. c., ed. de la Ac., 414). Es decir, la ley moral se refiere a la voluntad racional y a las operaciones racionales, y exige que sean conformes a ella. Esto, empero, significa que la razón práctica no sólo reconoce una ley práctica, sino que además tiene que referirla a la realidad, y por cierto ya dentro de la ley práctica (en cuanto exigencia), como también en la aplicación de la misma. Ésta exige "universalidad de una ley absolutamente", "con la cual debe ser conforme la máxima de la operación, única conformidad que representa al imperativo como necesario" (F. m. c., ed. de la Ac., 421). Se podría formular así: " $Q$ Que la universalidad sea efectiva en las operaciones racionales! La exigencia de la ley moral se dirige a una "relación de la razón con la voluntad" ( $R$. pr., 99); exige, según esto, un poner-en-relación el ser racional en que aparece. "Puesto que la universalidad de la ley, conforme a la cual se verifican efectos, constituye lo que en el sentido más general (según la forma) se llama propiamente naturaleza, es decir, la existencia de las cosas, $[\ldots]$ por eso el $[\ldots]$ imperativo podría [...] también expresarse así: obra de tal manera como si la máxima de tu acción debiera convertirse mediante tu voluntad en ley natural universal" (F. m. c., ed. de la Ac., 421). Ahora bien, es fácil de advertir que la forma como la razón pone esta relación con la existencia de las cosas es diferente, en el modus, de aquella en que pone como exigencia la ley práctica. Lo uno es la posición de una exigencia; lo otro, la posición de una síntesis enteramente determinada entre ley práctica y existencia: "determinación mediante ley" - como Kant la llama. 
La relación de la ley práctica, y de lo exigido en ella, con la existencia, sin embargo, es fundamentalmente de otra clase que la del dominio teorético: es una "determinación práctica", cuyo especial carácter tiene que ser muy bien visto. Las indicaciones de Kant, sobre cómo es efectuada por la razón esta determinación práctica, son muy escasas y, de cualquier manera, no reflexionadas metódicamente.

Se trata, en efecto, de una determinación de la voluntad y, mediante ésta, del obrar, y mediante ambos, de una realidad. Kant escribe: "pero además de la relación en que se halla el entendimiento con los objetos (en el conocimiento teorético), tiene también una con la facultad apetitiva, que [...] se llama voluntad, y voluntad pura, en cuanto que el entendimiento puro (que en tal caso se llama razón) es práctico por la sola representación de una ley" ( $R$. pr., g6). "Pero en el concepto de una voluntad está ya contenido el concepto de una voluntad, está ya contenido el concepto de la causalidad y, por ende, en el de una voluntad pura, el concepto de una causalidad con libertad, [que] en la ley pura práctica justifica a priori perfectamente su realidad objetiva, mas (como es fácil de comprender) no a efecto del uso teorético de la razón, sino del meramente práctico" ( $R . p r ., 96)$.

Si meditamos sobre lo que Kant dice aquí, se encuentra que el estado de cosas no es en absoluto tan "fácil de comprender", como Kant nos asegura. Tiene uno que preguntar: 1. ¿Qué se afirma? 2. ¿Cómo se lo afirma? 3. ¿Por medio de que principio se afirma?

Todavía la expresión más exacta de Kant es ésta: se afirma una determinación práctica mediante la ley práctica. Pero esto significaría una síntesis totalmente determinada, en que una "existencia", la facultad apetitiva, por ejemplo, entra en contacto con algo exigido $=$ voluntad.

Con ello se ofrece un primer resultado esencial: esta síntesis no puede concebirse ni de un modo puramente teorético, ni de un modo puramente práctico, pues precisamente es una síntesis mixta. El principio metódico de la filosofía trascendental exige que sea mostrada la condición de posibilidad de esa síntesis mixta. Tal mostración metódica, sin embargo, jno se encuentra en Kant! Una vez reconocido esto, puede señalarse con facilidad cómo precisamente a consecuencia de la falta de semejante discusión fundamental, Kant fluctúa en sus indicaciones. Por una parte, debe tratarse de posiciones de la razón práctica; por otra, Kant mismo indica que se trata ahí de "presuposiciones teoréticas". Pero con todo, éstas deben ser hechas "solamente en el aspecto práctico". Mas, como se señaló en el ejemplo de la voluntad, no se trata ni de síntesis puramente teoréticas, ni de una posición práctica en forma de exigencia moral en la ley práctica, sino de una sintesis de índole peculiar: Debe y es forman una trabazón que en el curso ulterior de estas exposiciones voy a designar como "efectividad". (El debe actúa en el es). También Kant, por lo demás, se sirve con frecuencia del giro de que 
la razón práctica es o debe ser efectiva. Su tendencia global, empero, apunta a concebir esa efectividad sólo como factum. Por una parte la concibe sólo como exigencia procedente de la ley moral (libertad como postulado); por otra parte, como formación, conformidad y sometimiento. El factum sólo debe "corresponder" a lo exigido - pero la ley moral, sin embargo, debe "tener causalidad" en alguna parte (a saber, en la voluntad).

El concepto de efectividad es el concepto de una sintesis de la ley práctica con una realidad, y por cierto en forma que la ley práctica determine realmente a la realidad. Esto sería lo que Kant llama libertad, a saber, "libertad práctica" (no "trascendental"). "Una voluntad libre y una voluntad bajo leyes morales son la misma cosa". (F. m. c., Sección 3). Es de esperar, naturalmente, que la filosofía crítica niegue la conocibilidad teorética de la libertad (es decir, respecto a su cómo). Sin embargo, puede señalarse aquí una relación análoga en el concepto de la causalidad. Kant mismo dice en efecto: "Cómo es posible semejante [capacidad de libertad], no es tan necesario poderlo contestar, porque igualmente, respecto a la causalidad según leyes naturales, hemos de contentarnos con conocer $a$ priori que ha de presuponerse tal causalidad, aun cuando no concibamos de ninguna manera cómo en virtud de una cierta existencia se pone la existencia de otro, y en ese caso hemos de atenernos exclusivamente a la experiencia" (R. p., $A, 449$ ). Si la categoría de causalidad, empero, es constitutiva, puede decirse lo mismo del concepto de la libertad práctica: es constitutivo para la efectividad (práctica).

La relación que domina aquí es cubierta por el frecuente giro kantiano: "sólo en el aspecto práctico". Este "sólo", en efecto, tiene a la vez para Kant, a consecuencia de su sobrevaloración de las ciencias naturales, un acento estimativo. Es en verdad una tarea esencial de la filosofía trascendental, aclarar la peculiar significación del conocimiento de la efectividad. Sin embargo, esto no se halla en la línea de la investigación dispuesta aquí por mí. Al menos Kant ha visto bien que el modus de conocimiento de la efectividad es diverso del modus "teorético", es decir, del modus de conocimiento de la mera facticidad. La expresión kantiana "sólo en el aspecto práctico", por tanto, puede también entenderse -y esta vez con derecho-, como limitación a otro modus del conocimiento.

Sin embargo, para el planteamiento problemático aquí abordado, resulta decisivo lo siguiente: que ha de reflexionarse asimismo sobre la relación de la ley pura práctica con la efectividad - pues para corresponder a la exigencia moral tenemos que saber si nuestro querer, nuestro obrar, y lo que él realiza, corresponde a la ley moral, y de qué manera.

El principio según el cual determinamos esta relación, lo utilizó por cierto también Kant en sus mismas reflexiones, pero no lo desarrolló metó dicamente hasta el fin. Es el principio de sentido. El concepto de sentido 
es el que sirve de fundamento a la reflexión (metódica) sobre la relación de la ley moral con la efectividad. Los juicios correspondientes son juicios sintéticos a priori mediante este principio.

Tiene que ser posible una síntesis de la atribución de sentido, si es que absolutamente debemos poder juzgar en este campo de manera responsable. Si en este respecto no fuera posible el conocimiento, la razón no podría ser prácticamente moral. Lo que afirmo es que con la relación de la ley moral con la realidad se pone al mismo tiempo una exigencia ulterior, que yo voy a señalar como exigencia de sentido.

Exigencia de sentido es exigencia de una realidad-ideal (realidad de lo debido, de lo ideal -e idealidad de lo real). Esta exigencia de sentido se extiende:

a) hacia atrás a la propia ley moral, en cuanto que la misma tiene relación con la efectividad;

b) a la efectividad;

c) a la relación que comprende a la ley práctica y a la efectividad.

En Kant entran en juego del modo más claro aquellas exigencias que se relacionan con la efectividad. Rezan así:

1) La efectividad tiene absolutamente que ser posible (postulado de la libertad).

2) En la efectividad y realidad tiene que poder ser realizada la exigencia de la ley práctica (postulados de Dios y de la inmortalidad -fin del bien supremo).

Respecto a 1) Kant escribe: la voluntad tiene que "poder conformarse con aquello a lo que debe someterse" (R. pr., 237). Es el postulado de la libertad. (Esta exigencia, por lo demás, está siempre realizada ya donde la ley moral y la ley de sentido se presentan en un ser racional finito).

Respecto a 2): La acción mandada, el fin mandado tienen que ser posibles. a) Sería "prácticamente imposible [...] tender hacia el objeto de un concepto, que en el fondo fuera vacío y sin objeto" (R. pr., 257). b) El hombre moral tiene que "querer que exista absolutamente un mundo, porque la ley moral requiere que el más al to [...] bien posible sea realizado" (Re. $I$. p. r., IX). c) "Es obligación hacer real el bien supremo según nuestra máxima capacidad; de ahí que deba ser también posible: por ende, es [...] también inevitable para todo ser racional presuponer aquello que es necesario para la objetiva posibilidad de aquél. La presuposición es tan necesaria como la ley moral" ( $R$. pr., 259; cf. también $R$. pr., 225). El bien supremo, por tanto, no sólo tiene que poder ser puesto como objeto por la razón, también tiene que ser realizable. Como es sabido, precisamente por ello pueden y tienen que ser postulados la inmortalidad y Dios.

Pero todavía se añade a esto el que la forma de la legalidad, que contiene a la ley práctica, excluye ya que el orden real, exigido en la máxima 
moral, sea contradictorio teorética o prácticamente. "Algunas operaciones son de tal índole que su máxima ni siquiera puede, sin contradicción, ser pensada como ley natural universal; y dista mucho que se pueda aun querer que algo semejante deba llegar a ser. En otras ciertamente no puede encontrarse aquella interna imposibilidad, pero con todo es imposible querer que su máxima sea elevada a la universalidad de una ley natural, porque una voluntad semejante se contradiría a sí misma" (F. m. c., ed. de la Ac., 424). - Como es generalmente sabido, Kant funda sobre estas presuposiciones su distinción de deberes perfectos e imperfectos. -El principio más universal que sirve de fundamento a estas determinaciones, lo formula Kant así: "Se tiene que poder querer que una máxima de nuestras acciones se convierta en ley universal" ( $F . m$. c., ed. de la $A c ., 424)$. En la prueba de las máximas se manifiesta que algunas de ellas "se aniquilarían a sí mismas como ley" (R. pr., 49).

Si la exigencia: "Se tiene que poder querer..." es aplicada no sólo a la posibilidad de una voluntad en general, a la posibilidad de una realización del fin final $y$, en ello, a la existencia posible de un mundo como condición de la misma, sino fundamentalmente a la relación de la ley práctica con la efectividad y realidad, entonces la exigencia de sentido se extiende tam. bién, según la afirmaciones de Kant, a la ley moral misma. Voy a citar una vez más el pasaje de la (R. pr., 205), porque contiene esta referencia expressis verbis: "Como [...] el fomento del bien supremo, que encierra en su concepto esta conexión [de la felicidad con la virtud en el mundo], es un objeto $a$ priori necesario de nuestra voluntad y está inseparablemente unido con la ley moral, por ello la imposibilidad del primero [del bien supremo] tiene que probar también la falsedad del segundo [de la ley moral]. Luego si el bien supremo es imposible según las reglas prácticas, también la ley moral, que lo manda fomentar, tiene que ser ilusoria [...] y por ende falsa en si" (R. pr., 205).

Así pues, se comprueba que el pasaje: "Se tiene que poder querer..." no sólo se refiere a la efectividad, sino también a la legitimidad de las exigencias morales para seres racionales finitos ("posibilidad de la fuerza obligatoria"). Ciertamente es de observar que esta exigencia de sentido sólo se aplica a esta relación de la ley práctica con la realidad, y no a la ley práctica puramente por sí. La última -y esto lo vio Kant a la vez que Rousseau, como el primero en la historia de la filosofía con claridad fundamental"no encierra ninguna condición a la que esté limitada" (F. m. c., ed. de la $A C ., 421$ ); manda "sin consideración a la naturaleza". Pero en tanto se aplica a la realización, cae dentro de las exigencias de sentido señaladas.

Una vez entendido esto, se plantea la pregunta de si con estas determinaciones, aun cuando en forma irreflexiva, aplicó Kant suficientemente en todas partes el principio de sentido. Ciertamente puede sospecharse de ante- 
mano que no es éste el caso, porque se sirve de aquél en forma metódicamente irreflexiva. Los momentos de la constitución suficiente, de la no infracción, de la libertad de contradicción de la exigencia, y de la validez objetiva que implica el concepto de sentido, ${ }^{1}$ fueron ciertamente atendidos, como se mostró; pero aún faltan en Kant, por encima de esto, los momentos de la totalidad y de la universalidad contenidos en el concepto de sentido. Sin embargo, por lo menos se encuentran puntos de arranque para ambos momentos.

El momento de universalidad aparece como "regla del juicio puro práctico": "Pregúntate a tí mismo, si en el caso de que la acción que te propones debiera suceder según una ley de la naturaleza, de la cual tú mismo fueras parte, podrías sin duda considerarla como posible mediante tu voluntad" (R. pr., 122). Imaginate "que pertenecieras a dicho orden de las cosas, ¿estarías acaso ahí con aceptación de tu voluntad?" ( $R$. pr., 123). Finalmente surge el momento de la totalidad en las siguientes-afirmaciones Kant: a) "En su aplicación práctica la razón" "busca [...] la totalidad incondicionada del objeto [...] bajo el nombre del bien supremo" (R. pr., 194). b) "La plena conformidad de los sentimientos con la ley moral [...] tiene [...] que ser posible [...] porque [...] está contenida en el mismo mandato" (R. pr., 219 y s.). Ciertamente Kant prosigue: "Ella es la santidad, una perfección de la que no es capaz ningún ser racional del mundo sensible en ningún momento de su existencia. Pero como a pesar de todo es postulada necesariamente como práctica, por eso sólo puede ser encontrada en un progressus tendiente al infinito hacia aquella plena conformidad" ( $R$. pr., 220). Esto cabalmente produce para Kant el postulado de la inmortalidad.

Pero si se obra radicalmente en serio respecto del momento de universalidad y totalidad -y. la exigencia de sentido lo implica-, entonces su repercusión va mucho 'más allá de lo que Kant señaló en sus Críticas. La ley de sentido, en efecto, exige la realización íntegra de la ley moral ("totalidad incondicionada", "conformidad perfecta"). Kant, no obstante, sin justificarlo, en parte restringió esta exigencia, en parte la extendió ilegitimamente. Aparece extendida de modo ilegítimo en la inclusión de la felicidad. La ley moral, según repetidas aseveraciones de Kant, exige sin duda sólo la universalidad de las acciones en virtud de un principio, pero ahí de ningún modo se trata de una adecuación de la felicidad al sentimiento moral. Kant llega a la exigencia de una adecuada felicidad sólo mediante una generalización empírica - no permitida críticamente:

"Ser feliz es necesariamente el anhelo de todo ser racional, pero finito, y por lo mismo un fundamento ineludible de determinación de su facultad apetitiva" (R. pr., 45). "El mandato de que alguien debiera procurar ha-

1 Cf. mi trabajo La pregunta por el sentido de la existencia (Munich, 1953), $1^{\text {a }}$ parte. 
cerse feliz a si mismo, sería insensato; pues no se manda jamás a alguien lo que él ya indefectiblemente quiere."

Kant argumenta asi: Todo hombre quiere ser feliz.

Ahora bien, la ley moral exige universalidad de lo querido.

Luego la ley moral exige universalidad de la felicidad.

La mayor de este silogismo, empero, es ilegítima. A más de esto, el razonamiento contiene aún una segunda falla. La ley moral manda - presupongamos esto con Kant- querer felicidad universal. Pero ahí no está aún resuelto que este querer logre también realidad en el mundo por encima de su propia efectividad. La conclusión: "El necesitar la felicidad, aun ser digno de ella, pero con todo no participar de la misma, no puede absolutamente coexistir junto con el querer perfecto de un ser racional que a la vez tuviera todo poder..." $(R$. pr., 199), por consiguiente, es correcta -obsequiada la suposición-, pero aquí no demuestra lo que debe demostrar. Pues tal conclusión implica todavia esta exigencia: la dicha debe ser adecuada a la moralidad en la realidad. Esta exigencia en ninguna parte fue deducida por Kant de la ley moral en forma concluyente. La ley moral exige sólo "la perfecta adecuación de los sentimientos", pero no la congruencia real de la dicha. Con esto cae al mismo tiempo también el postulado de "Dios", es decir, de un realizador de esta congruencia.

Por otro lado, sin embargo, Kant restringió injustificadamente el momento de la totalidad. Pues si la exigencia de la ley moral es total, habrá de volverse tambićn inevitablemente contra toda inmoralidad. La ley moral se convierte así en un juicio constante y terrible sobre la inmoralidad propia y ajena, y exige indefectiblemente su eliminación, aun cuando haya ocurrido atrás en el pasado; pues la ley moral no está restringida a condiciones algunas de la empirie. Con las palabras del salmo: Iniquitatem meam ego cognosco, et peccatum meum contra me est semper. El argumento de que tal eliminación es imposible, aducido por Kant mismo en la Religión dentro de los limites de la pura razón, es ineficaz. La ley moral exige expiación de la culpa (Omnes iniquitates meas dele!). Y según el propio punto de partida de Kant ha de decirse: o "Es imposible cumplir esta exigencia." Pero entonces se tiene que seguir concluyendo también que la ley moral es vacla y fantástica, "por ende, falsa en sí". O "Esta exigencia puede cumplirse". Entonces, jse postula con ello una salvación!

La correspondiente aplicación de la exigencia de totalidad al postulado de la inmortalidad, según esto, es evidente. La ley moral exige totalidad de la moralidad ("santidad"). Si ésta es imposible en aquel ser al que se manifiesta la ley moral, entonces es vacía, fantástica y falsa. (Entonces tampoco puede darse ninguna aproximación, y como en principio no es posible, tampoco importa que sea realizada sólo en forma temporal-finita. Otros seres racionales finitos podrían entrar en lugar de los terminados y - defec- 
tos inevitables - llenar su lugar de realización - una consecuencia a la que la filosofía de la historia de Kant se orienta en forma arriesgada). Si aquella es posible, entonces nuevamente tiene que ser postulada una salvación, esta vez como indestructibilidad de una moralidad perfecta.

Felicidad y adecuación de la dicha a la moralidad podría Kant exigirlas sólo si debiera atribuirse a la ley moral otro contenido y, así, otra significa. ción a la felicidad. Cuando Kant, en una anotación (l) al prólogo de la Critica de la razón práctica, dice: "Se me podría hacer todavía un reparo: porque tampoco aclaré anteriormente el concepto de la facultad apetitiva o de la sensación del placer; si bien, este reproche sería injusto, porque esta aclaración, como dada en la psicología, debería en justicia poder suponerla" ( $R$. pr., 15 y s., Nota), es una excusa muy insuficiente. Pues esto sería así, si la factultad apetitiva fuera un puro factum, lo cual, sin embargo, por los fundamentos aducidos arriba, es inaceptable. Ahora bien, si en el apetito sensible y en el sentimiento correspondiente a él se manifiesta la voluntad, entonces, una crítica de la razón práctica requeriría una deducción de aquélla, porque la ley moral se relaciona con la voluntad. Pero de este modo la relación de la voluntad moral con el apetito sensible permanece en lo esencial inconocible.

Queda todavia una última pregunta gnoseológica: hemos visto que Kant opera implícitamente con el concepto de sentido, desarrollando postulados desde él, y que sin embargo no conoció la significación metódica de este concepto, ni lo dedujo trascendentalmente. ¿Se sirvió aquí Kant de un principio a priori, o tal vez sólo de uno logrado mediante generalización empírica, o de uno inventado? Como Kant no emplea, absolutamente, el concepto de sentido expressis verbis - a la palabra "sentido" se le reservan en sus obras otros contenidos de significación-, tampoco se encuentra en su obra una respuesta directa a esta pregunta. Sin embargo, es claro, en virtud de mi análisis, que el concepto de sentido, así como el concepto de efectividad, es teórico-práctico. La razón práctica tiene "por sí principios originarios a priori, con los que ciertas posiciones teoréticas están inseparablemente enlazadas" ( $R$. pr., 216). Sin embargo, Kant no nombra el principio que hace posible el enlace. En su obra crítica total Kant deduce una razón teorética y una práctica - y deduce los principios constitutivos de las mismas. Pero no ofrece nada que baste para el conocimiento de que en ambas ramas es UNA razón la que pone estos principios. Ciertamente él mismo dice: es, "con todo, siempre sólo una y la misma razón la que, sea en intención teorética o práctica, juzga según principios a priori” (R. pr., 218), pero no va más allá de la comprobación fáctica de esta unidad. Con la exigencia planteada aquí críticamente se habrá logrado algo, sin duda, sólo en caso de que el principio de la unidad de la razón pueda hacerse comprensivo genéticamente. Como lo lleva a cabo Fichte en la Doctrina de la Ciencia del año 1804: "Si esta $y$ 
es inexplorable, puede siempre contener el nexo: yo por lo menos no la puedo penetrar como tal nexo, y no puedo concebir mediatamente los dos miembros complementarios, como procedentes de ella. [...] Por eso Kant no corrigió en manera alguna aquello de que lo culpamos con el último golpe decisivo a su sistema doctrinal, sino que sólo lo confesó francamente y él mismo lo descubrió" (O.P. II, 104).

Lo que Kant señaló muy claramente en este respecto, es: 1. Que en las "posiciones teoréticas" resultantes de los postulados, se presupone sin duda "realidad objetiva"; "con lo cual, en efecto, el conocimiento teorético de la razón pura recibe en verdad un aumento, que sin embargo sólo consiste en que aquellos conceptos, de otro modo problemáticos (meramente pensables) para ella, son aclarados ahora asertóricamente como tales y corresponden a ellos objetos reales [...] (R. pr., 242); 2. Que esta realidad, empero, es afirmada "sólo en un sentido práctico", y sólo en este aspecto se verifica una ampliación de nuestro conocimiento. Pero Kant no vio que este ensanchamiento exige por cierto una intuición, a saber, la de la voluntad, intuición de la voluntad (de la efectividad, como la he llamado yo) que funda ciertamente un saber de clase diversa a la intuición en el campo teorético, esto es, ningún saber teorético (en la significación kantiana de la palabra), sino sensible, llamado por Kant "práctico", en este sentido muy impropiamente y provocando en forma directa una quaternio.

En este saber se asienta qué y cómo una efectividad se conduce respecto de una exigencia moral. Nuestras afirmaciones existenciales son de esta clase. Tales afirmaciones, sin embargo, son posibilitadas en sentido crítico sólo mediante el concepto de sentido; son afirmaciones de sentido. Si se puede demostrar que la razón no puede ser teoréticamente sin ser práctica - es decir, aplicada a la verdad mediante la voluntad-, entonces la presuposición para que la razón exista absolutamente, es que sea práctica. Pero no puede, como se demostró, ser práctica sin que se asiente una efectividad y se aplique en el concepto de sentido a la exigencia práctica. El concepto de sentido tiene entonces seguramente un carácter constitutivo a priori. Este carácter constitutivo -a priori también se deduce, por otro lado, de que sus momentos pueden ser desarrollados válidamente "antes de toda experiencia". En la filosofía trascendental, por tanto, el concepto de sentido queda justificado críticamente como a priori.

Los postulados tendrían entonces que presentarse como hechos de la conciencia en la experiencia común y originariamente también como afirmaciones no teoréticas. Éste es además realmente el caso. Sirva aquí de ejemplo el modo como surge en el libro de Job la afirmación de inmortalidad como afirmación de sentido - no como resultado de una especulación teorética: 
Apiadaos de mi, apiadaos de $\mathrm{mi}$, al menos vosotros, mis amigos, iPues la mano de Dios me ha tocadol

¿Por qué queréis también vosotros perseguirme igual que Dios,

Por qué no os cansáis de descarnarme?

¡Oh! si mis palabras fueran inscritas,

Fueran anotadas en un libro

Con buril de bronce sobre plomo.

Queden para siempre grabadas en las rocas:

"Yo sé que mi Salvador vive.

Él, el último, se levantará sobre el polvo.

Y cuando mi piel no exista, a la que se haya desgarrado,

Libre de mi carne contemplaré a Dios,

Yo mismo lo veré hacia mi indulgente.

$\mathrm{Y}$ cuando mis ojos lo hayan contemplado, ya no seré enemigo;

En anhelo hacia ello se consumen mis entrañas (XIX, 21-27).

En Sófocles se pueden encontrar con facilidad los analoga en el medio pagano.

Concluyo respondiendo en forma resumida a la pregunta suscitada al principio de estas disquisiciones:

Kant afirma postulados, y esto (sin saberlo) por medio del concepto de sentido.

Fácticamente los afirma de manera legítima - pues junto a la relación de la exigencia moral con la realidad en la ley práctica, funge a priori evidentemente la ley de sentido, desde la cual se desarrollan estos postulados.

Metódicamente los afirma de manera ilegítima, porque ni demostró críticamente ni justificó el concepto de sentido, por lo cual tampoco desarrolla sus momentos metódica y universalmente.

Sus postulados, por ende, en parte no son reconocidos como tales, en parte son incompletos o demasiado amplios. La filosofía trascendental, empero, permite y exige un desarrollo metódico del concepto de sentido y una aplicación trascendental del mismo, es decir, un desarrollo de los postulados.

Los postulados reciben con ello otro valor trascendental.

REINHARD LAUTH

(Trad. de Bermabe Navarro B.) 